\title{
Structural Characterization, Global and Local Electrochemical Activity of Electroless Ni-P-Multiwalled Carbon Nanotube Composite Coatings on Pipeline Steel
}

\author{
Mara Cristina Lopes de Oliveira ${ }^{1}$, Olandir Vercino Correa ${ }^{2}$, Rejane Maria Pereira da Silva ${ }^{2}$, \\ Nelson Batista de Lima ${ }^{2}$, Jefferson Thadeu Dias de Oliveira ${ }^{1}$, Leandro Antônio de Oliveira ${ }^{1}$ \\ and Renato Altobelli Antunes $1, *$ (D) \\ 1 Center for Engineering, Modeling and Applied Social Sciences (CECS), Federal University of the \\ ABC (UFABC), Santo André 09210-580, SP, Brazil; mara.oliveira@ufabc.edu.br (M.C.L.d.O.); \\ jefferson.oliveirah@gmail.com (J.T.D.d.O.); antoli.leandro@gmail.com (L.A.d.O.) \\ 2 IPEN/CNEN-SP, Av. Prof. Lineu Prestes 2242, Cidade Universitária, São Paulo 05508-000, SP, Brazil; \\ ovcorrea@ipen.br (O.V.C.); rejanep2silva@gmail.com (R.M.P.d.S.); nblima@ipen.br (N.B.d.L.) \\ * Correspondence: renato.antunes@ufabc.edu.br; Tel.: +55-1-4996-8241
}

\section{check for} updates

Citation: de Oliveira, M.C.L.; Correa O.V.; da Silva, R.M.P.; de Lima, N.B.; de Oliveira, J.T.D.; de Oliveira, L.A.; Antunes, R.A. Structural

Characterization, Global and Local Electrochemical Activity of Electroless Ni-P-Multiwalled Carbon Nanotube Composite Coatings on Pipeline Steel. Metals 2021, 11, 982. https://doi.org/10.3390/met11060982

Academic Editor: Aleksander Lisiecki

Received: 27 May 2021

Accepted: 17 June 2021

Published: 20 June 2021

Publisher's Note: MDPI stays neutral with regard to jurisdictional claims in published maps and institutional affiliations.

Copyright: (c) 2021 by the authors. Licensee MDPI, Basel, Switzerland. This article is an open access article distributed under the terms and conditions of the Creative Commons Attribution (CC BY) license (https:/ / creativecommons.org/licenses/by/ $4.0 /)$.

\begin{abstract}
In this work, composite Ni-P-multiwalled carbon nanotube films were produced by electroless deposition. The main goal was to investigate the influence of multiwalled carbon nanotube loading on the local electrochemical behavior of the composite films, as probed by scanning electrochemical microscopy (SECM). The coatings were also characterized with respect to their crystalline structure, surface, and cross-section morphologies. Adhesion strength was examined by scratch tests. The global electrochemical behavior was evaluated by potentiodynamic polarization. The local electrochemical activity was investigated by probing the $\mathrm{Fe}^{2+}$ oxidation in the surface generation/tip collection mode of the SECM. The results revealed that multiwalled carbon nanotubes increased the adhesion strength and reduced the electrochemical activity on the surface of the coated samples.
\end{abstract}

Keywords: Ni-P/MWCNT composite coatings; electroless deposition; corrosion; scanning electrochemical microscopy

\section{Introduction}

Pipeline steels are manufactured from high-strength low-alloy steels (HSLA) to meet the strict requirements of the oil and gas industry with respect to its increasing demand for weight reduction and enhanced productivity in the transportation of their products [1,2]. The intrinsically high mechanical strength of HSLA steels accounts for their reliable operation in oilfield production [3]. Notwithstanding, the harsh environments to which they are subject pose challenging design issues related to both wear and corrosion control [4,5]. In view of the critical role played by HSLA steels in the safe operation of transmission pipelines, it is of prime importance to properly manage surface properties and to guarantee long-term operation without failure [6].

Corrosion is particularly pointed as a major cause of degradation of the load bearing capacity of HSLA transmission pipelines [7]. Coatings have been traditionally employed to protect the internal tubing walls from corrosion in the petroleum industry $[8,9]$. Epoxybased organic coatings are often employed with this purpose due to their chemical inertness and strong adhesion to metallic substrates [10]. It is well-known, though, that these materials lose their barrier properties with time, allowing electrolyte penetration through pores and flaws and, ultimately, to adhesion failure [11].

Electroless nickel coatings have emerged as a viable alternative to overcome the above-mentioned limitations [12]. These coatings are based on conventional binary Ni$\mathrm{P}$ films and have consolidated engineering applications in the automotive, aerospace, and food industries [13]. They owe their outstanding performance to a combination of 
strong adhesion in a variety of substrates, shapes and sizes, and high hardness in the annealed state, due to the precipitation of nickel phosphides promoting good wear and corrosion resistance [14,15]. In recent decades, further developments in the electroless deposition of nickel-based coatings have been driven by growing needs for optimized surface properties of metallic materials to expand their applicability to more aggressive environments. Ternary, quaternary, and composite coatings have been developed with this purpose [16-19]. Co-deposition of a variety of inorganic particles has been tested for the electroless plating of Ni-P composite coating, such as $\mathrm{SiO}_{2}, \mathrm{SiC}, \mathrm{TiO}_{2}, \mathrm{ZrO}_{2}$ and $\mathrm{B}_{4} \mathrm{C}$ [20-24].

Carbon nanotubes (CNT) have also been employed to reinforce particles for electroless Ni-P coatings. Several authors $[25,26]$ reported that multiwalled carbon nanotubes (MWCNT) improved the friction and wear properties of conventional electroless Ni-P. In addition to improved wear behavior, corrosion resistance is often reported as being favorably affected by incorporating CNT particles into the Ni-P matrix. The intrinsic chemical inertness and high length-to-diameter ratio of the CNTs would account for the optimized corrosion protection ability of the Ni-P-CNT coatings $[27,28]$. The ability of the CNT particles to block pores and cavities in the coating layer is associated with the improved barrier properties of the composite coatings [29,30].

In the present work, we expand the current knowledge related to the development of electroless Ni-P/MWCNT coatings by evaluating the local electrochemical activity using scanning electrochemical microscopy (SECM). Its use as an analytical tool to investigate local corrosion processes of a variety of metallic alloys has been reported in the literature. Both uncoated and coated alloys have been probed [31,32]. SECM can detect the local electrochemical activity associated with nucleation of pits, dissolution of metallic inclusions, and defects through coatings [33-35]. In this respect, for the first time we report the assessment of the local electrochemical activity of Ni-P/MWCNT composite coatings by SECM. Furthermore, Ni-P/MWCNT on HSLA pipeline steels is innovative. In order to support discussion on the electrochemical results, film structure and adhesion properties of the deposited layers were also evaluated.

\section{Materials and Methods}

\subsection{Substrate and Coating Preparation}

API 5L X80 pipeline steel (Usiminas, Ipatinga, MG, Brazil) was employed as substrate. Its chemical composition is shown in Table 1. Specimens were cut from the as-received plate into rectangular pieces with the final dimensions of $30 \mathrm{~mm} \times 30 \mathrm{~mm} \times 5 \mathrm{~mm}$. Before deposition, the specimens were ground with silicon carbide waterproof paper up to grit 1200. Next, the surface was cleaned with alcohol, rinsed with deionized water, and dried with a heat gun.

Table 1. Chemical composition of the API 5L X80 steel plate (wt.\%).

\begin{tabular}{cccccccccc}
\hline $\mathbf{C}$ & $\mathbf{M n}$ & $\mathbf{S i}$ & $\mathbf{P}$ & $\mathbf{S}$ & $\mathbf{N b}$ & $\mathbf{A l}$ & $\mathbf{C r}$ & $\mathbf{V}$ & $\mathbf{F e}$ \\
\hline 0.04 & 1.75 & 0.20 & 0.02 & 0.002 & 0.065 & 0.025 & 0.11 & 0.025 & Bal. \\
\hline
\end{tabular}

Electroless deposition was accomplished by preparing a Ni-P plating bath consisting of nickel sulfate $\left(30\right.$ g.L $\left.\mathrm{L}^{-1}\right)$, nickel hypophosphite $\left(40 \mathrm{~g} . \mathrm{L}^{-1}\right)$, sodium citrate $\left(10 \mathrm{~g} . \mathrm{L}^{-1}\right)$, acetic acid $\left(10 \mathrm{~mL} . \mathrm{L}^{-1}\right)$, lactic acid $\left(10 \mathrm{~mL} . \mathrm{L}^{-1}\right)$, and sodium hydroxide $\left(40 \mathrm{~g} . \mathrm{L}^{-1}\right)$. Sodium dodecyl sulfate $\left(2\right.$ g. $\left.\mathrm{L}^{-1}\right)$ was added to facilitate dispersion of the multiwalled carbon nanotubes in the bath. The bath was operated at $88^{\circ} \mathrm{C}$ and was magnetically stirred during deposition. The $\mathrm{pH}$ was 4.5 , adjusted with ammonium hydroxide. Multiwalled carbon nanotubes (MWCNT) were purchased from the Federal University of Minas Gerais (Brazil). Three different CNT concentrations were added to the plating bath: 0.25 g.L $\mathrm{L}^{-1}$, 0.50 g. $\mathrm{L}^{-1}$, and 1.0 g. $\mathrm{L}^{-1}$. These samples are designated as CNT-0.25, CNT-0.50, and CNT-1.0 throughout the text. 
Before deposition, the specimens were cleaned in an alkaline solution consisting of 10 wt. $\% \mathrm{NaOH}$ at $50{ }^{\circ} \mathrm{C}$ and activated in a $50 \%$ vol. $\mathrm{H}_{2} \mathrm{SO}_{4}$ solution at room temperature. After washing with deionized water, the specimens were immersed in the plating bath. The total deposition time was $2 \mathrm{~h}$. After deposition, the specimens were annealed at $400{ }^{\circ} \mathrm{C}$ for $1 \mathrm{~h}$ in a tubular furnace under argon atmosphere, followed by cooling inside the furnace.

\subsection{Structural, Morphological and Adhesion Characterization}

The crystalline character of the Ni-P/MWCNT composite coatings was assessed by $X$-ray diffractometry (Rigaku DMAX-2000) in the $\theta-2 \theta$ configuration, employing Cu-k $\alpha$ radiation. The $2 \theta$ range was from $20^{\circ}$ to $70^{\circ}$. The surface morphology and cross-sections of the different coatings were examined by scanning electron microscopy (SEM) coupled to an X-ray energy dispersive spectrometer (EDS) to study the elemental composition at the coating/substrate interface.

The adhesion strength of the Ni-P/MWCNT layers was evaluated through scratch tests by means of a Ducom T101 apparatus equipped with a Rockwell C-type diamond tip. The normal load was continuously increased from $1 \mathrm{~N}$ to $38 \mathrm{~N}$ at a rate of 2 N.min ${ }^{-1}$, a scratch velocity of $0.5 \mathrm{~mm} . \mathrm{s}^{-1}$, and a total scratch length of $10 \mathrm{~mm}$. Confocal laser scanning microscopy (Olympus, LEXT OLS4100) was employed to evaluate the penetration depth of the indenter and topographic features at the interface between the unscratched and scratched regions.

\subsection{Global and Local Electrochemical Tests}

Conventional electrochemical tests were carried out using an Autolab M101 potentiostat/galvanostat. A classical three-electrode cell set up was employed with a platinum wire as the auxiliary electrode, $\mathrm{Ag} / \mathrm{AgCl}$ as the reference, and the coated API 5L X80 specimens as the working electrodes. The tests were performed in $3.5 \mathrm{wt} \% \mathrm{NaCl}$ solution at room temperature. Initially, the open circuit potential was monitored for $1 \mathrm{~h}$. Right after, electrochemical impedance spectroscopy measurements were made at the OCP in the frequency range from $100 \mathrm{kHz}$ to $10 \mathrm{mHz}$. The amplitude of the perturbation signal was $\pm 10 \mathrm{mV}$ and the acquisition rate was 10 points per decade. Next, the samples were subject to potentiodymamic polarization by sweeping the potential between $-300 \mathrm{mV}$ versus the OCP up to $+1,0 \mathrm{~V}_{\mathrm{Ag} / \mathrm{AgCl}}$ at $1 \mathrm{mV} . \mathrm{s}^{-1}$.

SECM current maps were acquired using a commercial Sensolytics system, operating in the substrate generation-tip collection mode (SG-TC). In this operation mode, electroactive species generated on the corroding surfaces are reduced or oxidized at the tip, providing the values of the current related to electrochemically active sites on the material [36,37]. The SG-TC operation mode was reported in the investigation of localized corrosion sites on the stainless steel $[33,38]$, whereby the selective monitoring of reacting species provided from the specific reactions required the operation of the corroding system without the need to insert a redox mediator to reach electrochemical responses. In this present work, the SG-TC operation mode was used to investigate the electrochemical activity of the studied material associated with the localized production of $\mathrm{Fe}^{2+}$ ions above the surfaces. Thus, $\mathrm{Fe}^{2+}$ ions produced from the corrosion of the material is sensed in an oxidation reaction at the Pt tip, according to Equation (1).

SECM current maps were acquired using a commercial Sensolytics system, operating in the substrate generation-tip collection mode (SG-TC). The reaction shown in Equation (1), which is typical of ferrous alloys corrosion in aqueous media [33,37], was probed by biasing the tip at $+600 \mathrm{~V}_{\mathrm{Ag} / \mathrm{AgCl}}$.

$$
\mathrm{Fe}^{2+} \leftrightarrow \mathrm{Fe}^{3+}+\mathrm{e}
$$

A glass-insulated $10 \mu \mathrm{m}$ diameter Pt microelectrode was used as the tip, $\mathrm{Ag} / \mathrm{AgCl}$ as the reference electrode, and a $\mathrm{Pt}$ wire as the auxiliary electrode. The specimens were mounted horizontally facing upwards. The tip was at a height of $30 \mu \mathrm{m}$ above the substrate surface. The potentials were controlled with a bipotentiostat coupled to the SECM system. 
The specimens were at the open circuit potential. The measurements were carried out in a $0.1 \mathrm{M} \mathrm{NaCl}$ solution at room temperature. The electrolyte was less concentrated than that used for the global electrochemical tests, as the results obtained in $3.5 \mathrm{wt} . \% \mathrm{NaCl}$ did not allow to distinguish the local electrochemical response of each sample by SECM due to excessively high current densities measured throughout the probed area.

\section{Results}

\subsection{X-ray Diffraction}

XRD patterns of the Ni-P and Ni-P/MWCNT composite coatings are shown in Figure 1.

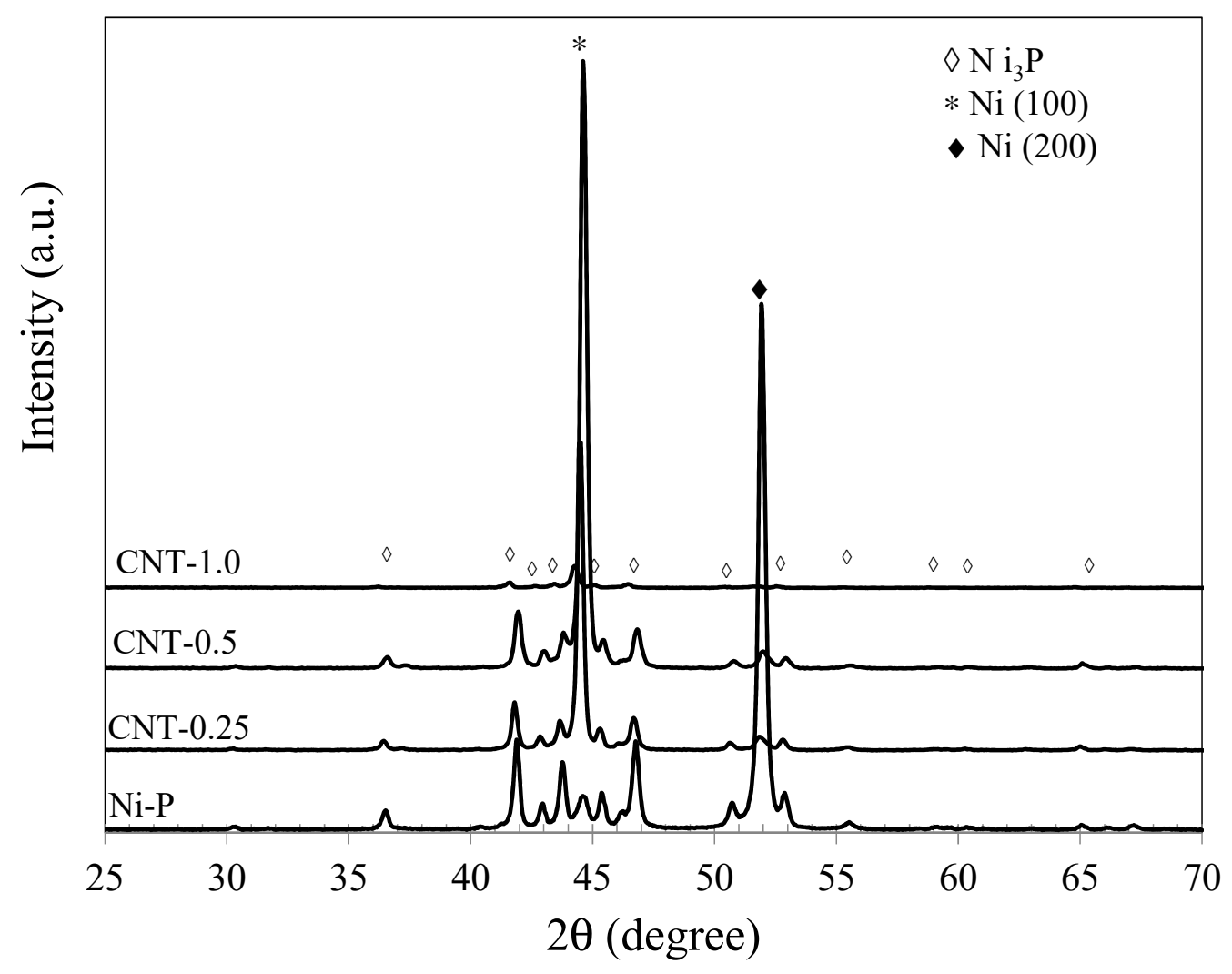

Figure 1. XRD patterns of the Ni-P and Ni-P/MWCNT coatings.

The presence of $\mathrm{Ni}_{3} \mathrm{P}$ crystallites is clearly observed in the pattern of the conventional $\mathrm{Ni}-\mathrm{P}$ film. These species are typical of electroless nickel coatings and are formed during annealing $[39,40]$. Strong reflections of the $\mathrm{Ni}(100)$ and (200) crystalline planes are also observed. The crystalline character of the composite coatings was affected by the carbon nanotubes. The strong Ni (200) reflection of the conventional Ni-P coating was markedly decreased for the Ni-P-CNT coatings, whereas the $\mathrm{Ni}(100)$ became the preferential orientation. Furthermore, the CNT-1.0 presented a steep reduction in the intensity of its diffraction peaks, indicating that the coating became less crystalline when CNT concentration was increased. This effect was observed by other authors [41], being attributed to a distortion of the crystalline nickel matrix by the incorporation of CNT particles.

\subsection{SURFACE and Cross-Section Morphology}

The morphology of the conventional Ni-P and Ni-P/MWCNT composite coatings was examined by scanning electron microscopy (SEM). Figure 2 shows the SEM micrographs (secondary electrons mode) of the top surfaces.

The binary Ni-P film displays a typical nodular morphology (Figure 2A). The nodular structure is associated with nucleation and growth of the deposit during electroless plating. A high nucleation rate is reported to enhance the number of nodules during deposition [42]. 
By adding the CNT filler into the plating, the nodules size became finer. The nodular morphology is less clearly perceived for CNT-0.25 (Figure 2B) due to their small size; this effect is enhanced for the coatings obtained in the baths with higher CNT loadings (Figure 2C,D). In this respect, the CNT particles tend to increase the nucleation rate during electroless deposition, as previously observed by $\mathrm{Xu}$ et al. [39]. As a consequence, the coating surface assumes a more compact character which, in turn, can affect the corrosion resistance in a positive way.
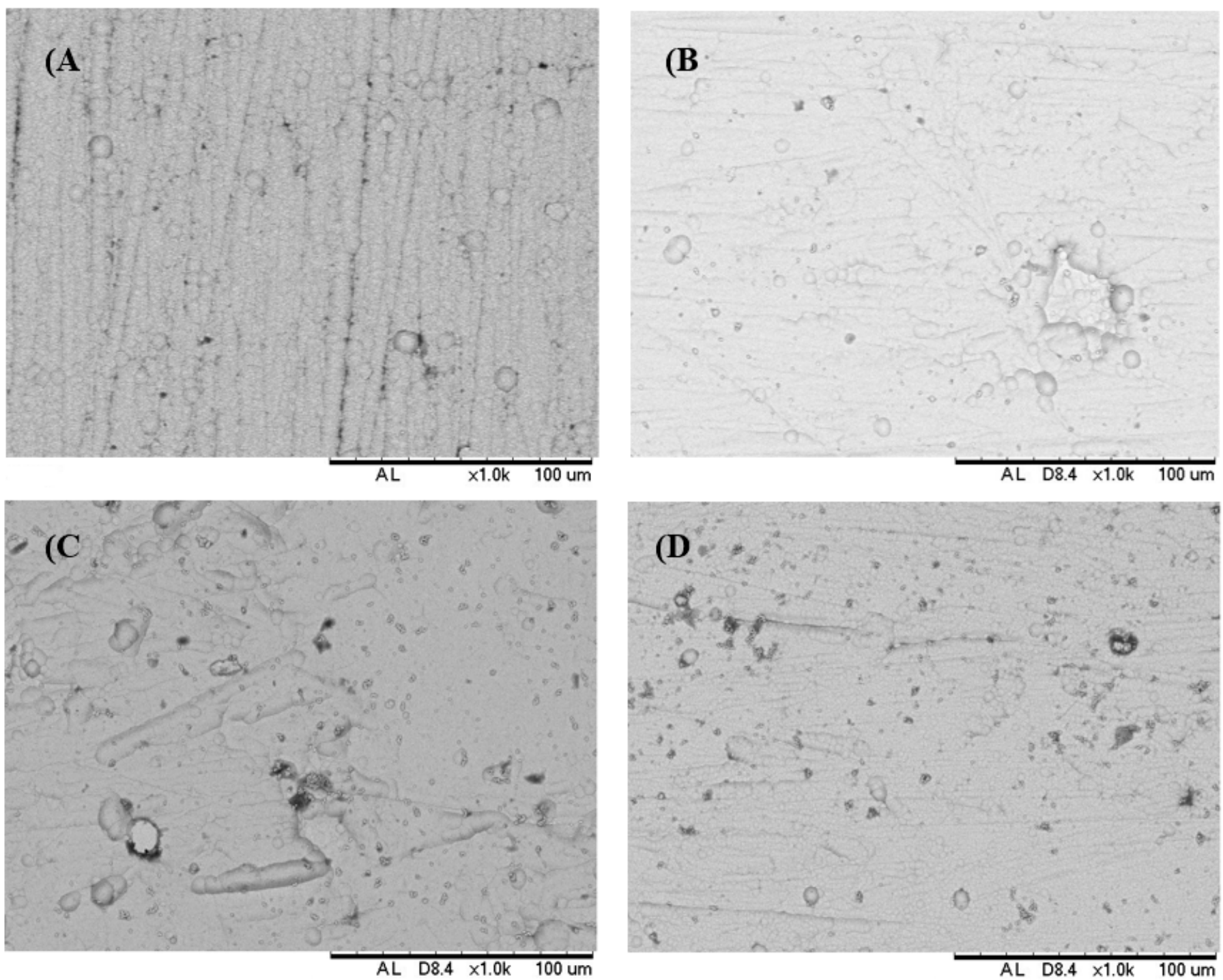

Figure 2. SEM micrographs of the top surfaces of the nickel-based coatings: (A) Ni-P; (B) CNT-0.25; (C) CNT-0.5; (D) CNT-1.0.

Coating thickness was examined by SEM/EDS analyses of the cross-sections. Figure 3 shows the results obtained for the CNT- 0.25 film. The results for the other samples are very similar (not shown) and are provided as supplementary files.

The interface between film and substrate can be clearly distinguished by examining Figure 3B (Ni mapping), Figure 3C (P mapping), and Figure 3D (Fe mapping). Coating thickness was approximately $4.5 \mu \mathrm{m}$. The coating follows a continuous interface with the substrate with no signs of broken-off sites, suggesting it is well-adhered. Similar features were observed for the other Ni-P/MWCNT films (Supplementary MaterialsFigure S1). Electroless nickel coatings are reported to present good adhesion to metallic substrates [40]. The results obtained in the present work point towards this direction. 
Additional characterization of the adhesion properties of the composite coatings was undertaken by scratch tests. The results are shown in Section 3.3.
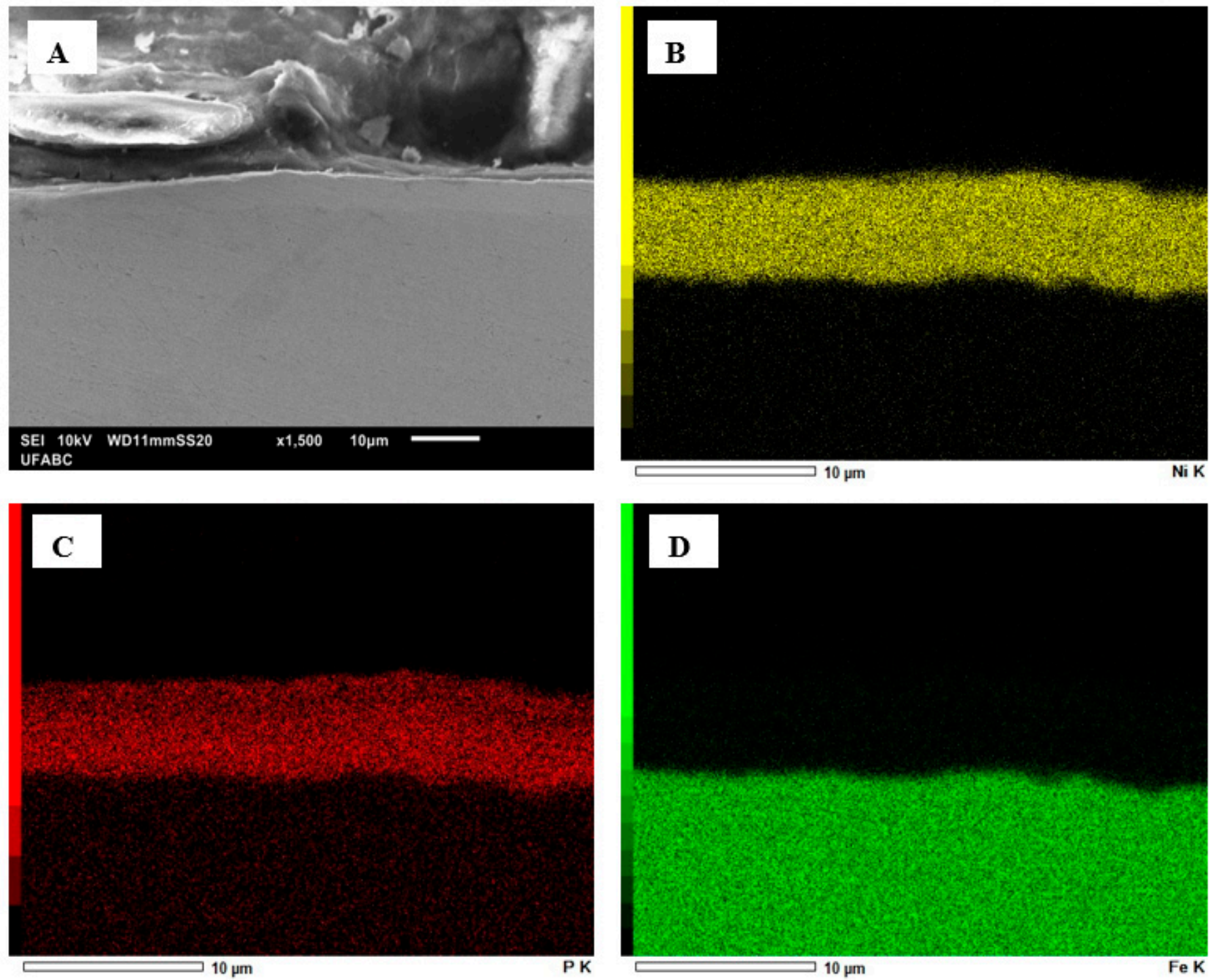

Figure 3. EDS mapping of the cross-sections for CNT-0.25: (A) SEM micrograph; (B) Ni; (C) P; (D) Fe.

\subsection{Scratch Tests}

Adhesion is a must-attend feature of protective coatings. In spite of its relevance, adhesion properties of Ni-P/MWCNT composite coatings are not commonly reported in the literature. The results obtained by scratch tests of the Ni-P and Ni-P/MWCNT coatings are shown in Figure 4. The CLSM 3D views of the scratched regions are shown as well as the transverse profiles along the lines marked in the 3D micrographs. The width (average of ten measurements over the scratch length) and maximum depth of the scratched regions were determined from these lines. The results are shown in Table 2. By evaluating the transverse profiles, it is evident that MWCNT loading greatly affected the scratched region. Both the width and the depth were reduced as the MWCNT loading in the plating bath increased. The shallowest scratch was measured for the CNT-1.0 sample which was also the narrowest one. The conventional Ni-P film, in turn, presented the deepest and widest scratch. This result points to the strong hardening effect of MWCNT addition into the Ni-P matrix, confirming the results obtained by other authors [43]. 

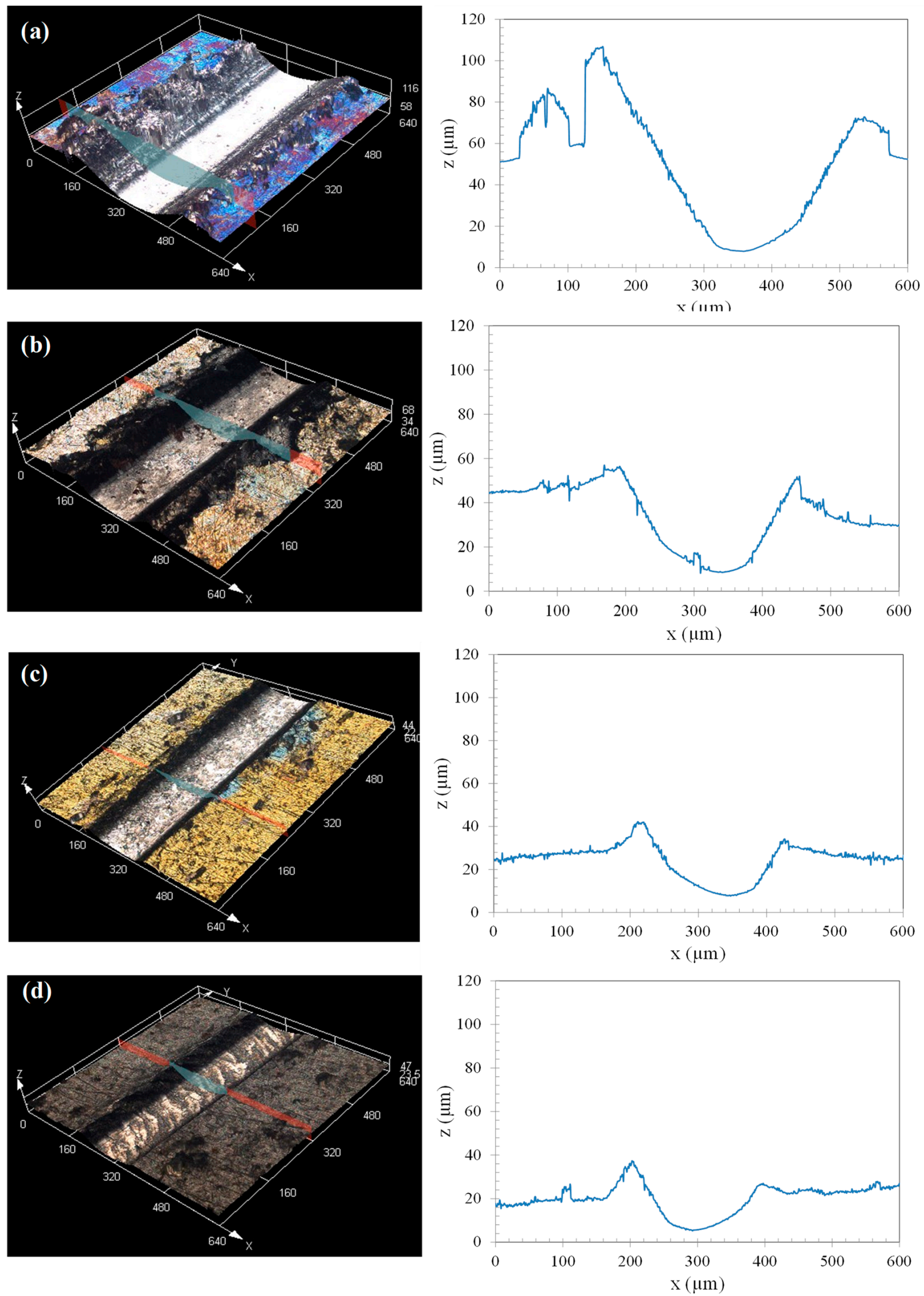

Figure 4. 3D views of the scratched region and the corresponding transverse profile along the lines marked in the micrographs: (a) Ni-P; (b) CNT-0.25; (c) CNT-0.5; (d) CNT-1.0. 
Table 2. Scratch dimensions of the Ni-P and Ni-P/MWCNT coatings.

\begin{tabular}{ccc}
\hline Sample & Width $(\mu \mathrm{m})$ & Maximum Depth $(\mu \mathrm{m})$ \\
\hline Ni-P & $538 \pm 35$ & 101 \\
\hline CB-0.25 & $442 \pm 27$ & 47 \\
\hline CB-0.50 & $252 \pm 24$ & 37 \\
\hline CB-1.0 & $188 \pm 3$ & 32 \\
\hline
\end{tabular}

The critical role played by MWCNTs in the adhesion strength of the Ni-P layer to the pipeline steel substrate is also perceived from the 3D views presented in Figure 4 . The conventional binary Ni-P coating was delaminated over the scratch length, as can be seen from the relatively wide dark region in the vicinity of the scratched area in Figure 4a. In spite of the reduction in both the scratch width and depth with respect to the Ni-P film, the CNT-0.25 film also presented a relatively wide dark region along the scratch, indicating that coating delamination (Figure $4 \mathrm{~b}$ ) had occurred in a similar way of that observed for the conventional unfilled Ni-P matrix. As the MWCNT loading increased, though, different features could be perceived along the scratch line. As seen in Figure 4c, the delaminated area was greatly reduced for the CNT- 0.50 sample in comparison with the CNT- 0.25 and $\mathrm{Ni}-\mathrm{P}$. Such a trend was also observed for the CNT-1.0 sample (Figure 4d). For this condition, the spalling area in the surroundings of the scratch scar is confined within a narrower region. Spalling avoidance is associated with a better mechanical load accommodation during scratch tests of nickel-based coatings [44]. In this respect, our results point that the CNT particles had a beneficial effect on the adhesion properties of the Ni-P/MWCNT composite coatings.

\subsection{Global Electrochemical Tests}

EIS results are represented as Nyquist plots, as shown in Figure 5. All samples are characterized by capacitive loops in the medium to low frequencies, whose diameter depends on the MWCNT loading in the coating. As pointed out in the literature, the corrosion resistance is associated with the diameter of the Nyquist plots, since it is associated with the polarization resistance of the electrode $[45,46]$. The uncoated substrate presented very low impedance values when compared to the coated samples. As a consequence, its Nyquist plot is only seen when the impedance scales are expanded, as shown in the inset of Figure 5. The impedance values were greatly enhanced for the coated samples, indicating its beneficial effect on the corrosion resistance of the steel substrate.

The Nyquist plot of the Ni-P exhibits a bigger diameter when compared to the uncoated sample, revealing the increased corrosion resistance imparted by the electrolessly deposited film. A progressive increase in the diameter of the Nyquist plot is observed by incorporating MWCTs into the Ni-P. The CNT-1.0 is the most corrosion-resistant, as suggested by its large capacitive loop.

The corrosion resistance of the Ni-P and Ni-P/MWCNT coated samples was further evaluated by potentiodynamic polarization tests after $1 \mathrm{~h}$ of immersion in $3.5 \mathrm{wt} . \% \mathrm{NaCl}$ solution at room temperature. The results are shown in Figure 6. The uncoated API 5L X80 steel substrate was also tested for comparison purposes. The corrosion potential ( $\mathrm{E}_{\mathrm{corr}}$ ) and corrosion current densities ( $i_{\text {corr }}$ ) were determined from these curves by means of the Tafel extrapolation method. The results are displayed in Table 3, along with the protection efficiency ( $\mathrm{P} \%$ ) of the different coatings, as calculated from Equation (2).

$$
P \%=\left(1-\frac{i_{\text {corr }}^{*}}{i_{\text {corr }}^{0}}\right) \times 100
$$

where $i_{\text {corr }}^{*}$ and $i_{\text {corr }}^{0}$ are the corrosion current densities of the coated and uncoated substrate, respectively. 


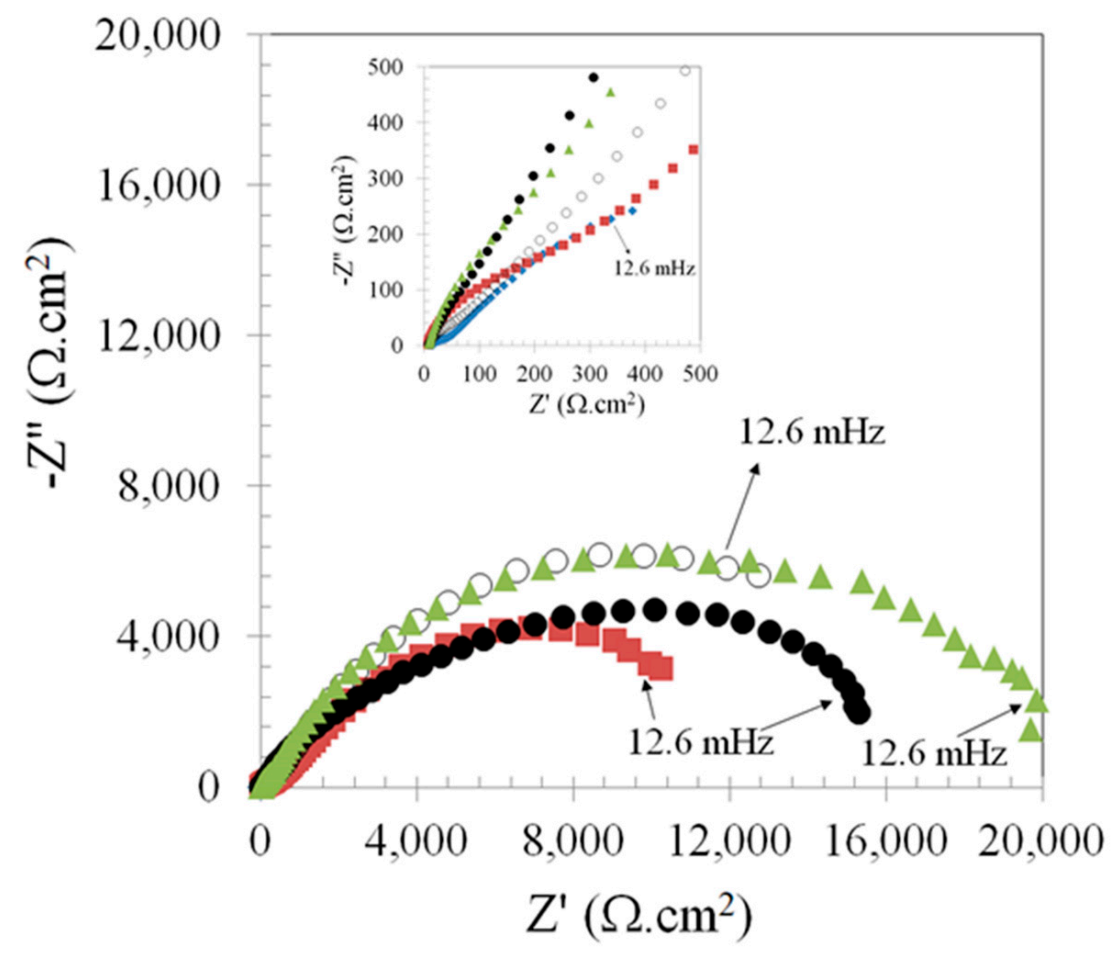

Figure 5. Nyquist plots of the Ni-P and Ni-P/MWCNT coatings after $1 \mathrm{~h}$ of immersion in 3.5 wt.\% $\mathrm{NaCl}$ solution at room temperature.

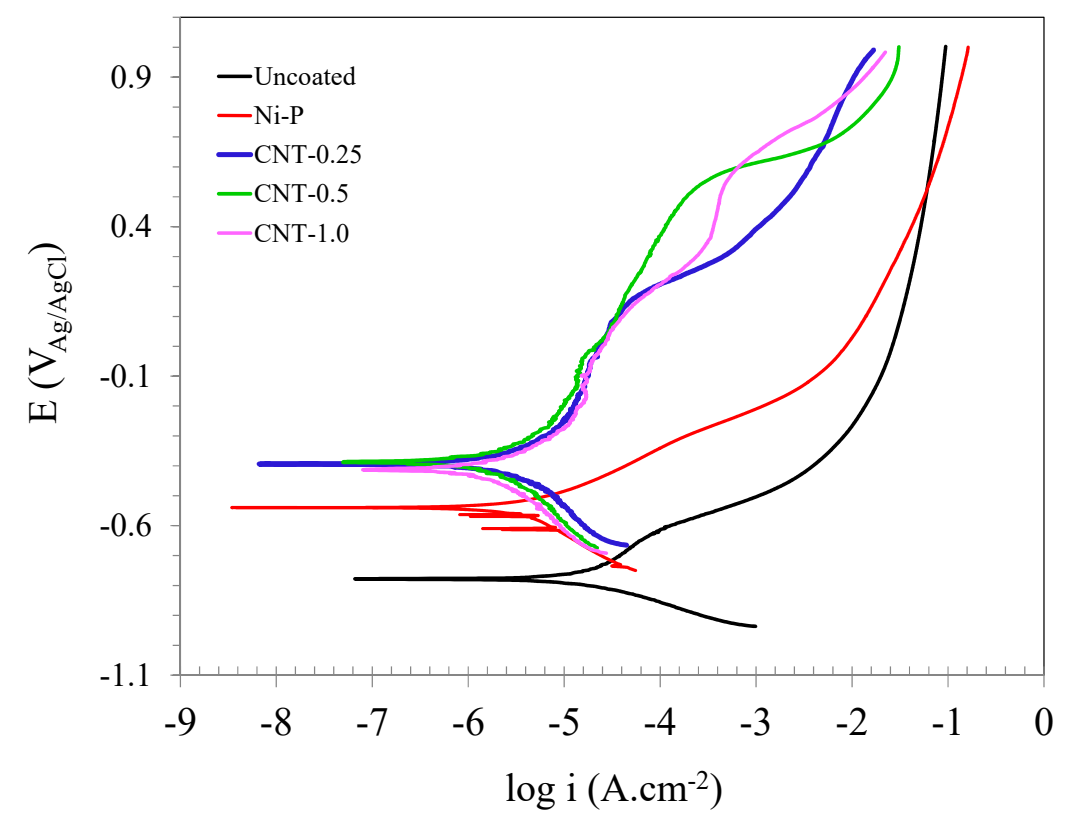

Figure 6. Potentiodynamic polarization curves of the Ni-P and Ni-P/MWCNT coatings after $1 \mathrm{~h}$ of immersion in $3.5 \mathrm{wt}$ \% $\mathrm{NaCl}$ solution at room temperature.

Table 3. Corrosion parameters of the uncoated substrate, Ni-P and Ni-P/MWCNT coatings.

\begin{tabular}{cccc}
\hline Coating & $\mathbf{E}_{\text {corr }}\left(\mathbf{m V}_{\mathbf{A g} / \mathbf{A g C l}}\right)$ & $\mathbf{i}_{\text {corr }}\left(\boldsymbol{\mu} \mathbf{A . c m} \mathbf{c m}^{-2}\right)$ & $p(\mathbf{\%})$ \\
\hline Uncoated & -778 & 20.3 & - \\
Ni-P & -540 & 4.17 & 79.5 \\
CNT-0.25 & -394 & 3.28 & 83.8 \\
CNT-0.5 & -388 & 2.38 & 88.3 \\
CNT-1.0 & -413 & 2.01 & 90.1 \\
\hline
\end{tabular}


The corrosion potential $\left(\mathrm{E}_{\mathrm{corr}}\right)$ of the conventional Ni-P coating was shifted to the nobler direction with respect to the uncoated substrate. This trend was also observed for the composite Ni-P/MWCNT films. Notwithstanding, there is no clear tendency of increasing $\mathrm{E}_{\mathrm{corr}}$ with the MWCNT loading. The electrochemical stability of the electrode surface is associated with $\mathrm{E}_{\mathrm{corr}}$, which increases as this parameter is shifted towards more anodic values [47]. The intrinsic low reactivity of carbon nanotubes [48] is likely to be responsible for the nobler $\mathrm{E}_{\text {corr }}$ values, compared with the uncoated substrate and the conventional Ni-P film.

All coatings markedly decreased the corrosion current density of the API 5L X80 steel substrate. The reduced $i_{\text {corr }}$ scaled with the carbon nanotube was loaded in the plating bath. The protection efficiency of each coating is also presented in Table 3, showing the higher protectivity of the CNT-1.0 condition. Moreover, the anodic currents are lower for the composite Ni-P/MWCNT films when compared to the conventional Ni-P layer. It is also noteworthy that the polarization curves of the composite films presented a well-defined passive region that is not seen for the uncoated substrate or the Ni-P film. Both the intrinsic chemical inertia of carbon nanotubes and the possibility of blocking small pores in the Ni-P matrix were reported as the main causes of the increased corrosion resistance of electroless Ni-P-CNT composite coatings [49].

\subsection{Scanning Electrochemical Microscopy (SECM)}

SECM 2D maps of the uncoated API5LX80 steel, Ni-P, and composite Ni-P/MWCNT coatings are shown in Figure 7. The maps were recorded in $0.1 \mathrm{M} \mathrm{NaCl}$ at room temperature. The tip was biased at $+600 \mathrm{mV}_{\mathrm{Ag} / \mathrm{AgCl}}$ to sense the formation of $\mathrm{Fe}^{2+}$ ions generated at the sample surface. The sample was unbiased.

During the corrosion process of this type of material, the oxidation of $\mathrm{Fe}^{2+}$ to $\mathrm{Fe}^{3+}$ occurs in the anodic sites, in which the $\mathrm{Fe}^{2+}$ ions are originated from the material dissolution. Thus, $\mathrm{Fe}^{2+}$ ions produced from the corrosion process are available on the surface. Thereby, when the Pt tip (polarized at $+600 \mathrm{mVAg} / \mathrm{AgCl}$ ) passes over the anodic sites, $\mathrm{Fe}^{2+}$ ions are oxidized to $\mathrm{Fe}^{3+}$, according to Equation (1). Hence, since $\mathrm{Fe}^{2+}$ production is a primary feature of the anodic regions on the surface, the SECM maps shown in Figure 6 display the electrochemical activity of the studied surfaces related to possible active domains of $\mathrm{Fe}^{2+}$ ions. Higher oxidation current values indicate greater electrochemical activity of the surface.

The SECM maps show current spikes where the electrochemical activity is higher at the probed surface. The uncoated substrate presented the highest currents over the whole area, indicating that the electrochemical activity is more intense when compared to the coated material. There is no preferential site for current spikes, suggesting that corrosion does not occur by a localized attack, which is in agreement with the potentiodynamic polarization curve shown in Figure 6 for the bare substrate.

The currents were significantly reduced for the Ni-P film, indicating the protective character of the electrolessly deposited layer, leading to a decrease in the electrochemical activity probed by the tip near the sample surface. The cathodic values of the measured currents confirm the low activity for $\mathrm{Fe}^{2+}$ oxidation.

Izquierdo et al. [50] reported that the cathodic currents can be due to the fact that once the concentration of $\mathrm{Fe}^{2+}$ ions is low at the metallic surface, these species are likely to be easily oxidized to $\mathrm{Fe}^{3+}$ before diffusing to the bulk electrolyte. The cathodic current would then be probed at regions where $\mathrm{Fe}^{3+}$ ions are formed according to reaction (1). The presence of such regions would indicate that the film, although presenting low electrochemical activity, is prone to corrosion at its defective sites. It is possible to see in the SECM map shown in Figure 7B that the current values vary throughout the surface, suggesting that it is not homogeneous with respect to the sites where $\mathrm{Fe}^{2+}$ oxidation occurs. 

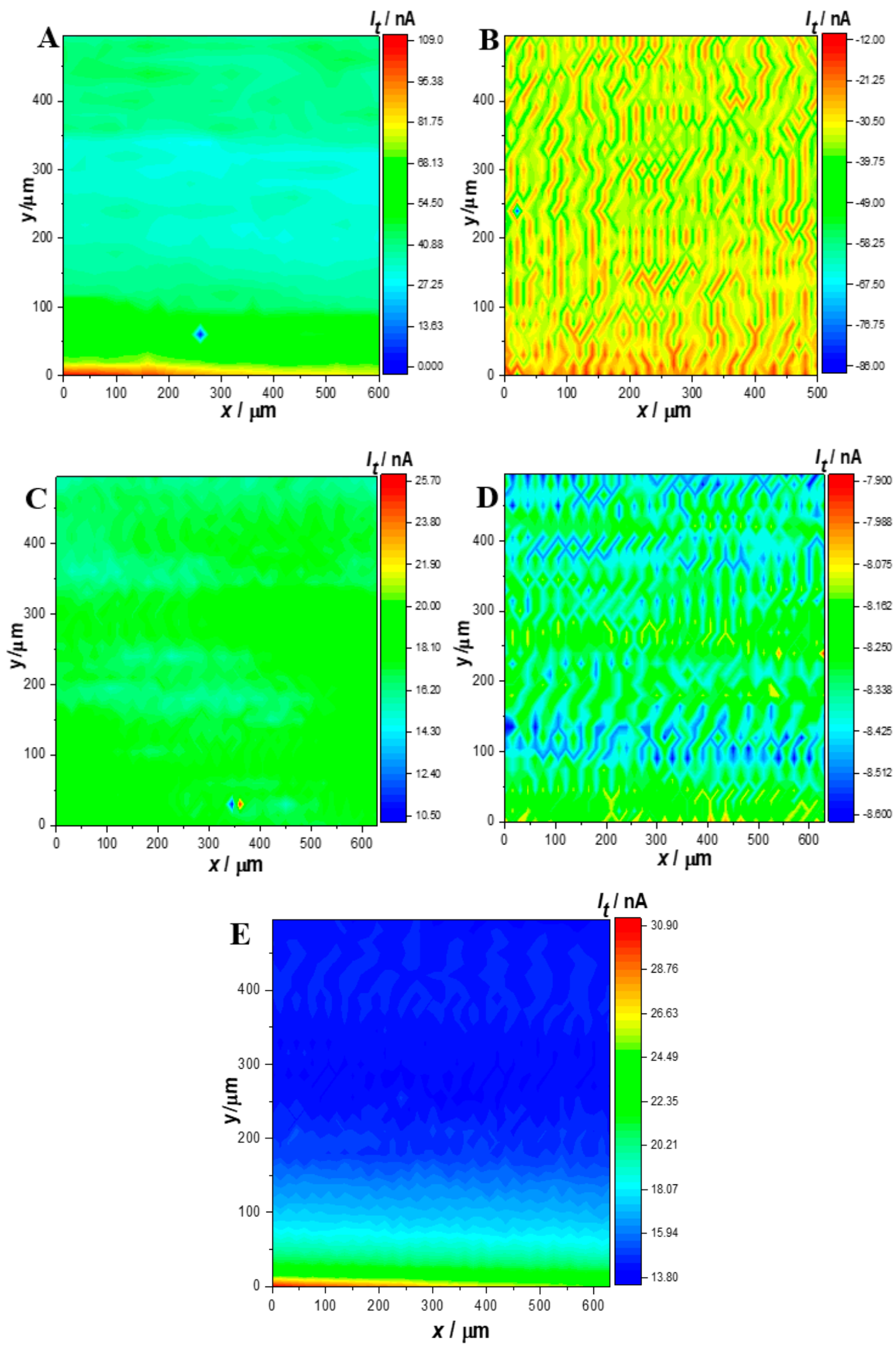

Figure 7. SECM 2D maps obtained with the tip biased at $+600 \mathrm{mV}_{\mathrm{Ag} / \mathrm{AgCl}}$ and the sample at the open circuit potential: (A) uncoated substrate; (B) Ni-P layer; (C) CNT-0.25; (D) CNT-0.50; (E) CNT-1.0. Electrolyte: $0.1 \mathrm{M} \mathrm{NaCl}$ solution at room temperature. 
The probed anodic currents are low on the surface of the CNT-0.25 sample (Figure 7C) when compared to the uncoated substrate, revealing the beneficial effect of carbon nanotubes in reducing the electrochemical activity of the metallic substrate. The current values are homogeneous over the probed area. The CNT-0.50 film, in turn, presented several current fluctuations on the SECM map and values that are slightly cathodic (Figure 7D). These low cathodic currents are likely due to the absence of the electroactive probed species $\left(\mathrm{Fe}^{2+}\right.$ ions), indicating the lower activity of the CNT-0.50 film when compared with the CNT-0.25 film. This result agrees well with the global electrochemical behavior described in the previous section.

The currents are predominantly anodic over the surface of the CNT-1.0 sample, as shown in Figure 7E. The maximum currents are low over most part of the probed area, as indicated by the blue color scale at the right part of the SECM map. Hence, the increment of CNT loading in the coating layer has led to a decrease in the electrochemical activity. This is unequivocally perceived by comparing CNT- 1.0 and CNT- 0.25 samples. Notwithstanding, the difference is not so obvious when CNT-1.0 and CNT-0.50 samples are compared, since their SECM maps indicate low electrochemical activity in both cases. This result is also in agreement with the evaluation of the global electrochemical behavior the by potentiodynamic polarization curves (Figure 6 and Table 3). SECM proved to be sensitive to the electrochemical activity of the composite Ni-P-CNT films. Our results suggest that CNT-0.50 would give a suitable performance with respect to the adhesion and corrosion properties of the composite films. CNT-1.0 gave the best overall performance.

\section{Discussion}

From the previous sections it was possible to observe that MWCNT incorporation decreased the anodic dissolution rate of the Ni-P layer, leading to a significant reduction in the electrochemical activity, as shown in the SECM maps displayed in Figure 7. As mentioned in Section 3.4, literature reports ascribe the beneficial effect of carbon nanotubes on reducing the corrosion rate of $\mathrm{Ni}-\mathrm{P}$-coated substrates to its blocking effect with respect to intrinsic coating defects [47]. Alishahi et al. [28] reported a reduction of approximately $55 \%$ in the corrosion current density of a Ni-P/MWCNT composite film, with respect to a conventional Ni-P layer in $3.5 \mathrm{wt} . \% \mathrm{NaCl}$ solution. Our results point to an even higher protection efficiency of the Ni-P/MWCNT layer. Based on these results, the proposed corrosion mechanism of the Ni-P/MWCNT coated samples is schematically illustrated in Figure 8.

Figure $8 \mathrm{~A}$ shows the corrosion mechanism of the conventional Ni-P binary coating where anodic dissolution of the steel substrate occurs through intrinsic coating defects such as pores as cracks, releasing $\mathrm{Fe}^{2+}$ ions to the electrolyte. In fact, the high electrochemical activity of this sample was observed in the SECM map displayed in Figure 7B, supporting the occurrence of this mechanism. A different scenario was established after MWCNT incorporation in the Ni-P matrix. The electrochemical activity was gradually reduced, as described in Section 3.5, slowing down the anodic dissolution rate of the steel substrate. As a consequence of the blocking effect of the MWCNT particles, the release of $\mathrm{Fe}^{2+}$ ions was gradually reduced. This situation is illustrated in Figure $8 \mathrm{~B}$ for the CNT- 0.25 sample. As the MWCNT loading in the composite film increased, the amount of $\mathrm{Fe}^{2+}$ ions released to the solution was further reduced. The progressively lower electrochemical activity of the CNT-0.50 (Figure 7D) and CNT-1.0 (Figure 7E) films would be a consequence of this effect, as illustrated in Figure 8C,D, respectively. 

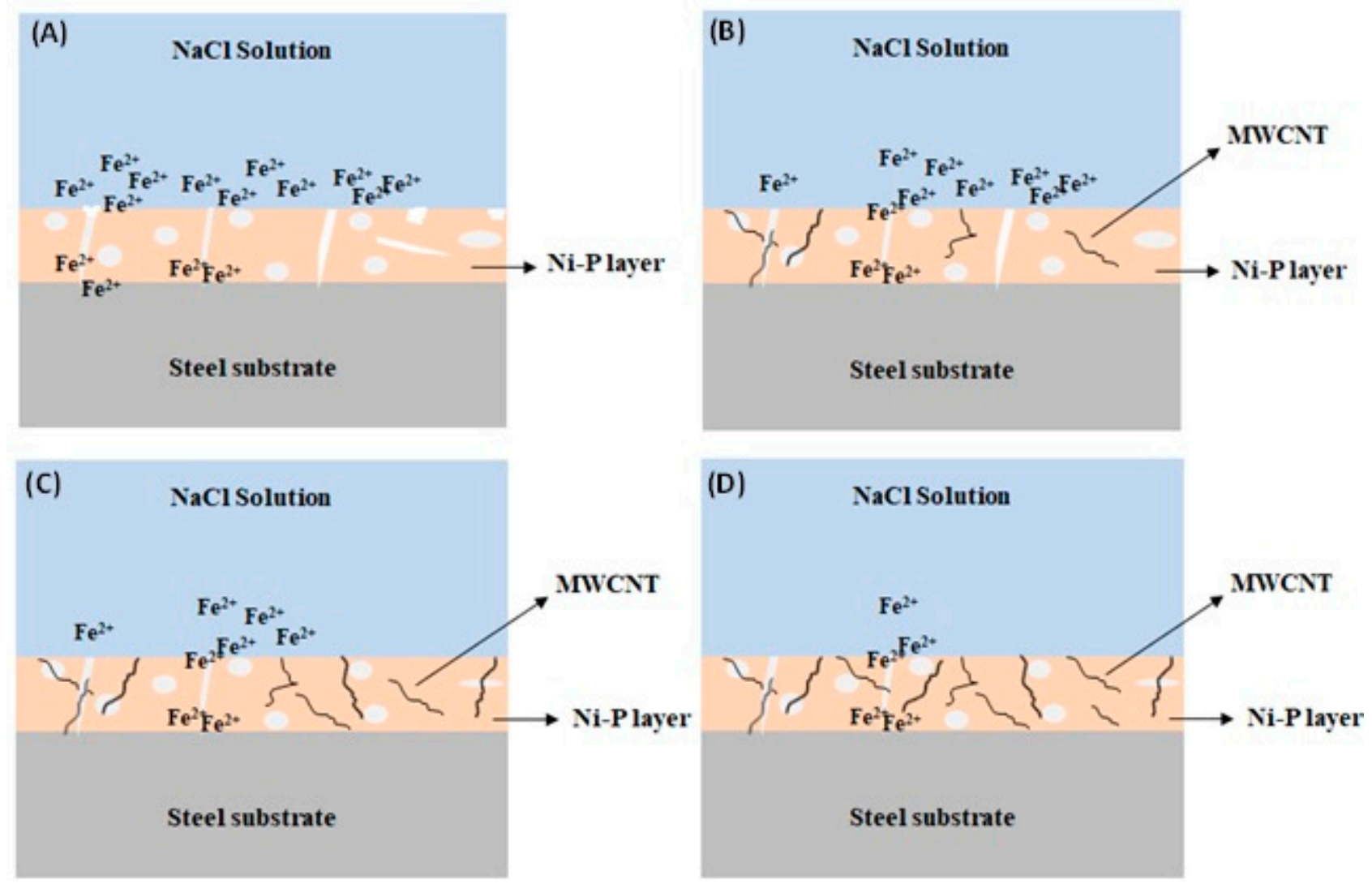

Figure 8. Schematic illustration of the corrosion mechanism of the Ni-P and Ni-P/MWCNT coatings: (A) Ni-P layer; (B) CNT-0.25; (C) CNT-0.50; (D) CNT-1.0.

\section{Conclusions}

Composite Ni-P/MWCNT films were successfully obtained by electroless deposition on the API 5L X80 substrate. MWCNT loading in the plating bath did not affect the thickness of the deposited layer, but reduced the size of the nodules on the coating, compared to the conventional binary Ni-P film. Adhesion strength was improved by adding the CNTs. The corrosion resistance of the composite films was increased due to the intrinsic low reactivity of the carbon nanotubes. This aspect was also evidenced by SECM analysis in the surface generation/tip collection mode (SG/TC). The SECM maps of the composite films with higher MWCNT loadings revealed low electrochemical activity for the $\mathrm{Fe}^{2+}$ oxidation reaction.

Supplementary Materials: The following are available online at https:/ / www.mdpi.com/article/10 $.3390 /$ met11060982/s1, Figure S1: EDS mapping of the cross-section for the CNT-0.50 film: (A) SEM micrograph; (B) Ni; (C) P; (D) Fe.; Figure S2: EDS mapping of the cross-section for the CNT-1.0 film: (A) SEM micrograph; (B) Ni; (C) P; (D) Fe.

Author Contributions: Conceptualization: M.C.L.d.O. and R.A.A.; Methodlogy: R.A.A., R.M.P.d.S and N.B.d.L.; investigatFion: J.T.D.d.O., O.V.C. and L.A.d.O.; Writing-original draft preparation: M.C.L.d.O. and R.A.A.; Supervision: R.A.A.; funding acquisition: R.A.A. All authors have read and agreed to the published version of the manuscript.

Funding: This research was funded by CNPq (Process 470944/2013-7).

Institutional Review Board Statement: Not Applicable.

Informed Consent Statement: Not Applicable.

Data Availability Statement: The data obtained in this study are available from the corresponding. 
Acknowledgments: Usiminas (Brzil) is kindly acknowledged for providing the pipeline steel used in this work. The Multiuser Experimental Facilities (UFABC) is acknowledged for the experimental support to this work.

Conflicts of Interest: The authors declare no conflict of interest.

\section{References}

1. Tanguy, B.; Luu, T.T.; Perrin, G.; Pineau, A.; Besson, J. Plastic and damage behavior of a high strength API5L X100 pipeline steel: Experiments and modeling. Int. J. Press. Vessel. Pip. 2005, 85, 322-335. [CrossRef]

2. Liu, Z.Y.; Cui, Z.Y.; Li, X.G.; Du, C.W.; Xing, Y.Y. Mechanistic aspect of stress corrosion cracking of X0 pipeline steel under non-stable cathodic polarization. Electrochem. Commun. 2014, 48, 127-129. [CrossRef]

3. Ituen, E.B.; Asuquo, J.E. Inhibition of X80 steel corrosion in oilfield acidizing environment using 3-(2-chloro-5,6-dihydrobenzol[b][1]benzaze 11-yl-)-N,N-dimethylpropan-1-amine and its blends. J. King Saud Univ. Sci. 2019, 31, 127-135. [CrossRef]

4. Xie, F.; Li, X.; Wang, D.; Wu, M.; Sun, D. Synergistic effect of sulphate-reducing bacteria and external tensile stress on the corrosion behavior of X80 pipeline steel in neutral soil environment. Eng. Fail. Anal. 2018, 91, 383-396. [CrossRef]

5. Islam, M.d.A.; Farhat, Z.N. Mechanical and electrochemical synergism of API X42 pipeline steel during erosion-corrosion. J. Bio. Tribo. Corros. 2015, 1, 26. [CrossRef]

6. Kong, D.; Wu, Y.; Long, D. Salt spray corrosion resistance of aluminized coatings on X70 pipeline steel by laser thermal radiation. Rare Met. Mat. Eng. 2014, 43, 2083-2088. [CrossRef]

7. Zeinoddini, M.; Mo'tamedi, M.; Zandi, A.P.; Talebi, M.; Shariati, M.; Ezzati, M. On the ratcheting of defective low-alloy, high-strength steel pipes (API-5L X80) under cyclic bending: An experimental study. Int. J. Mech. Sci. 2017, 130, 518-533. [CrossRef]

8. Yang, X.-H.; Zhu, W.-L.; Lin, Z.; Huo, J.-J. Aerodynamic evaluation of an internal epoxy coating in nature gas pipeline. Prog. Org. Coat. 2005, 54, 73-77. [CrossRef]

9. Wang, C.; Farhat, Z.; Jarjoura, G.; Hassan, M.K.; Abdullah, A.M. Indentation and bending behavior of electroless Ni-P-Ti composite coatings on pipeline steel. Surf. Coat. Technol. 2018, 334, 243-252. [CrossRef]

10. Darmiani, E.; Danaee, I.; Rashed, G.R.; Zaarei, D. Formulation and study of corrosion prevention behavior of epoxy cerium nitrate-montmorillonite nanocomposite coated carbon steel. J. Coat. Technol. Res. 2013, 10, 493-502. [CrossRef]

11. Abdou, M.I.; Ayad, M.I.; Diab, A.S.M.; Hassan, I.A.; Fadl, A.M. Influence of surface modified ilmenite/melamine formaldehyde composite on the anti-corrosion and mechanical properties of conventional polyamine cured epoxy for internal coating of gas and oil transmission pipelines. Prog. Org. Coat. 2017, 113, 1-14. [CrossRef]

12. Krishnan, K.H.; John, S.; Srinivasan, K.N.; Praveen, J.; Ganesan, M.; Kavimani, P.M. An overall aspect of electroless Ni-P depositions-A review article. Metall. Mater. Trans. A 2006, 37, 1917-1926. [CrossRef]

13. Fayyad, E.M.; Abdullah, A.M.; Hassan, M.K.; Mohamed, A.M.; Wang, C.; Jarjoura, G.; Farhat, Z. Synthesis, characterization, and application of novel Ni-P-carbon nitride nanocomposites. Coatings 2018, 8, 37. [CrossRef]

14. Oliveira, M.C.L.; Correa, O.V.; Ett, B.; Sayeg, I.J.; Lima, N.B.; Antunes, R.A. Influence of the tungsten content on surface properties of electroless Ni-W-P coatings. Mater. Res. 2018, 21, 1-13. [CrossRef]

15. Goettems, F.S.; Ferreira, J.Z. Wear behavior of electroless heat treated Ni-P coatings as alternative to electroplated hard chromium deposits. Mater. Res. 2017, 20, 1300-1308. [CrossRef]

16. Roy, S.; Sahoo, P. Optimization of electroless Ni-P-W coatings for minimum friction and wear using grey-Taguchi method. J. Coat. 2013, 2013, 608140. [CrossRef]

17. Liao, Y.; Zhang, S.T.; Dryfe, R. A study of corrosion performance of electroless Ni-P and Ni-W-P coatings on AZ91D magnesium alloy. Materialwiss. Werkst. 2011, 42, 833-837. [CrossRef]

18. Balaraju, J.N.; Selvi, V.E.; William Grips, V.K.; Rajam, K.S. Electrochemical studies on electroless ternary and quaternary Ni-P based alloys. Electrochim. Acta 2006, 52, 1064-1074. [CrossRef]

19. Cissé, M.; Abouchane, M.; Anik, T.; Himm, K.; Belakhimima, R.A.; Touhami, M.E.; Touir, R.; Amiar, A. Corrosion resistance of electroless Ni-Cu-P ternary alloy coatings in acidic and neutral corrosive mediums. Int. J. Corros. 2010, 2010, 246908. [CrossRef]

20. Sadreddini, S.; Afshar, A. The effect of heat treatment on properties of Ni-P-SiO 2 nano-composite coating. Prot. Met. Phys. Chem. Surf. 2016, 52, 492-499. [CrossRef]

21. Islam, M.; Azhar, M.R.; Khalid, Y.; Khan, R.; Abdo, H.S.; Dar, M.A.; Oloyede, O.R.; Burleigh, T.D. Electroless Ni-P/SiC nanocomposite coatings with small amounts of SiC nanoparticles for superior corrosion resistance and hardness. J. Mater. Eng. Perform. 2015, 24, 4835-4843. [CrossRef]

22. Gadhari, P.; Sahoo, P. Study of wear behavior of Ni-P-TiO 2 composite coatings by optimizing coating parameters. Mater.Today: Proc. 2017, 4, 1883-1892. [CrossRef]

23. Yang, Y.; Chen, W.; Zhou, C.; Xu, H.; Gao, W. Fabrication and characterization of electroless Ni-P-ZrO 2 nano-composite coatings. Appl. Nanosci. 2011, 1, 19-26. [CrossRef]

24. Araghi, A.; Paydar, M.H. Wear and corrosion characteristics of electroless Ni-W-P-B ${ }_{4} \mathrm{C}$ and Ni-P-B ${ }_{4} \mathrm{C}$ coatings. Tribol. Mater. Surf. Interfaces 2014, 8, 146-153. [CrossRef]

25. Chen, X.H.; Peng, J.C.; Li, X.Q.; Deng, F.M.; Wang, J.X.; Li, W.Z. Tribological behavior of carbon nanotubes-reinforced nickel matrix composite coatings. J. Mater. Sci. Lett. 2001, 20, 2057-2060. [CrossRef] 
26. Meng, Z.-Q.; Li, X.-B.; Xiong, Y.-J.; Zhan, J. Preparation and tribological performances of Ni-P-multiwalled carbon nanotubes composite coatings. Trans. Nonferrous Met. Soc. China 2012, 22, 2719-2725. [CrossRef]

27. Zarebidaki, A.; Allahkaram, S.R. Effect of surfactant on the fabrication and characterization of Ni-P-CNT composite coating. J. Alloy. Compd. 2011, 509, 1836-1840. [CrossRef]

28. Alishahi, M.; Monirvaghefi, S.M.; Saatchi, A.; Hosseini, S.M. The effect of carbon nanotubes on the corrosion and tribological behavior of electroless Ni-P-CNT composite coating. Appl. Surf. Sci. 2012, 258, 2430-2446. [CrossRef]

29. Chen, X.H.; Chen, C.S.; Xiao, H.N.; Cheng, F.Q.; Zhang, G.; Yi, G.J. Corrosion behavior of carbon nanotubes-Ni composite coating. Surf. Coat. Technol. 2005, 191, 351-356. [CrossRef]

30. Yang, Z.; Xu, H.; Li, M.K.; Shi, Y.L.; Huang, Y.; Li, H.L. Preparation and properties of Ni/P/single-walled carbon nanotubes composite coatings by means of electroless plating. Thin Solid Films 2004, 466, 86-91. [CrossRef]

31. Marques, A.G.; Izquierdo, J.; Souto, R.M.; Simões, A.M. SECM imaging of the cut edge corrosion of galvanized steel as a function of pH. Electrochim. Acta 2015, 153, 238-245. [CrossRef]

32. Singh, A.; Ansari, K.R.; Kumar, A.; Liu, W.; Chen, S.; Lin, Y. Electrochemical, surface and quantum Chemical studies of novel imidazole derivatives as corrosion inhibitors for J55 steel in sweet corrosive environment. J. Alloys Compd. 2017, 712, 121-133. [CrossRef]

33. Yin, Y.; Niu, L.; Lu, M.; Guo, W.; Chen, S. In situ characterization of localized corrosion of stainless steel by scanning electrochemical microscope. Appl. Surf. Sci. 2008, 255, 9193-9199. [CrossRef]

34. Paik, C.H.; White, H.S.; Alkire, R.C. Scanning electrochemical microscopy detection of dissolved sulfur species from inclusions in stainless steel. J. Electrochem. Soc. 2000, 147, 4120-4124. [CrossRef]

35. Xia, D.-H.; Wang, J.; Wu, Z.; Qin, Z.; Xu, L.; Hu, W.; Behnamian, Y.; Luo, J.-L. Sensing corrosion within an artificial defect in organic coating using SECM. Sens. Actuators B 2019, 280, 235-242. [CrossRef]

36. Bastos, A.C.; Simões, A.M.; González, S.; González-García, Y.; Souto, R.M. Imaging concentration profiles of redox-active species in open-circuit corrosion processes with the scanning electrochemical microscope. Electrochem. Commun. 2004, 6, 1212-1215. [CrossRef]

37. Völker, E.; Inchauspe, C.G.; Calvo, E.J. Scanning electrochemical microscopy measurement of ferrous ion fluxes during localized corrosion of steel. Electrochem. Commun. 2006, 8, 179-183. [CrossRef]

38. González-García, Y.; Burstein, G.T.; González, S.; Souto, R.M. Imaging metastable pits on austenitic stainless steel in situ at the open circuit corrosion potential. Electrochem. Commun. 2004, 6, 637-642. [CrossRef]

39. Xu, S.; Hu, X.; Yang, Y.; Chen, Z.; Chan, Y.C. Effect of carbon nanotubes and their dispersion on electroless Ni-P under bump metallization for lead-free solder interconnection. J. Mater. Sci. Mater. Electron. 2014, 25, 2682-2691. [CrossRef]

40. Xie, G.; Liu, S.; Guo, D.; Wang, Q.; Luo, J. Investigation of the running-in process and friction coefficient under the lubrication of ionic liquid/water mixture. Appl. Surf. Sci. 2009, 255, 6408-6414. [CrossRef]

41. Li, Z.H.; Wang, X.Q.; Wang, M.; Wang, F.F.; Ge, H.L. Preparation and tribological properties of the carbon nanotubes-Ni-P composite coating. Tribol. Int. 2006, 39, 953-957. [CrossRef]

42. Balaraju, J.N.; Kalavati; Rajam, K.S. Surface morphology and structure of electroless ternary NiWP deposits with various W and P contents. J. Alloys Compd. 2009, 486, 468-473. [CrossRef]

43. Wang, Q.; Callisti, M.; Miranda, A.; McKay, B.; Deligkiozi, I.; Milickovic, T.K.; Zoikis-Karathanasis, A.; Hrissagis, K.; Magagnin, L.; Polcar, T. Evolution of structural, mechanical and tribological properties of Ni-P/MWCNT coatings as a function of annealing temperature. Surf. Coat. Technol. 2016, 302, 195-208. [CrossRef]

44. Alexis, J.; Gaussens, C.; Etcheverry, B.; Bonino, J.-P. Development of nickel phosphorus coatings containing micro particles of talc phyllosilicates. Mater. Chem. Phys. 2013, 137, 723-733. [CrossRef]

45. Hamdy, A.S.; El-Shenawy, E.; El-Bitar, T. Electrochemical impedance spectroscopy study of the corrosion behavior of some niobium bearing stainless steels in 3.5\% NaCl. Int. J. Electrochem. Sci. 2006, 1, 171-180.

46. El-Sayed, M.S. Comparative study on the electrochemical corrosion behavior of iron and X-65 steel in $4.0 \mathrm{wt}$.\% sodium chloride solution after different exposure intervals. Molecules 2014, 19, 9962-9974. [CrossRef]

47. Serdar, M.; Zulj, L.V.; Bjegovic, D. Long-term corrosion behaviour of stainless reinforcing steel in mortar exposed to chloride environment. Corros. Sci. 2013, 69, 149-157. [CrossRef]

48. Praveen, B.M.; Venkatesha, T.V.; Naik, Y.A.; Prashantha, K. Corrosion studies of carbon nanotubes-Zn composite coating. Surf. Coat. Technol. 2007, 201, 5836-5842. [CrossRef]

49. Yang, Z.; Xu, H.; Shi, Y.-L.; Li, M.-K.; Huang, Y.; Li, H.-L.; Huang, Y.; Li, H.-L. The fabrication and corrosion behavior of electroless Ni-P-carbon nanotube composite coatings. Mater. Res. Bull. 2005, 40, 1001-1009. [CrossRef]

50. Izquierdo, J.; Martín-Ruíz, L.; Fernández-Pérez, B.M.; Rodríguez-Raposo, R.; Santana, J.J.; Souto, R.M. Scanning microelectrochemical characterization of the effect of polarization on the localized corrosion of 304 stainless steel in chloride solution. $J$. Electroanal. Chem. 2014, 728, 148-157. [CrossRef] 